\title{
The Application of Input and Output Theory to Primary English Teaching
}

\author{
Li Wanlu
}

\author{
Bachelor of Arts in English \\ Beijing Normal University \\ No. 19, Xinjiekouwai Street, Haidian District, Beijing 100875 China \\ e-mail65131889@qq.com
}

\begin{abstract}
Primary school is a critical period for children's language learning, so foreign language teaching in this period is particularly important. Primary school English education is an important part of the nine-year compulsory education in China. It is also very important for junior high school and high school learning. Primary school English education belongs to the research category of second language acquisition, and there have been rich research results on second language acquisition. According to data, from 2000 to 2020 (10 years as a search unit), nearly 20,000 articles were published, of which articles on primary school English education are 7,589 accounted for nearly 35\%. These studies mainly focus on English input theory such as Krashen theory or English output theory such as Swain's theory but are rare to import Combined with output theory.

China has always attached great importance to primary school English education and has achieved great results. Through searching the domestic ChinaNet, it was found that there are as many as 1,500 literatures related to primary education. In recent years, primary school English teaching has been advancing continuously in reforms, but primary school English teaching methods suitable for Chinese situation have yet to be studied and verified. Language input theory and language output theory are currently influential and profound theories in second language acquisition theories at home and abroad. Their scientific nature and effectiveness have been proven through various practices. Many domestic scholars have also conducted research on how to apply input theory and output theory to foreign language teaching, but their research objects are concentrated in universities and middle schools. Few scholars combine these two theories with elementary school teaching, and few studies have combined input theory and output theory to solve teaching problems. Therefore, this article will be based on two theories of language input and output, combined with Fillmore's theory of children's cognitive development, to improve corresponding language input and output teaching methods for pupils of different ages.
\end{abstract}

Keywords: education, input and output theory, primary english

\section{LITERATURE}

\subsection{The Input Theory to Primary English Teaching}

Since the 1990s, domestic research on input, including research on related teaching methods, has been continuously carried out. These researches are mainly concentrated in the following aspects. From a theoretical perspective, some scholars have carried out a series of studies on input methods. Ding Guocheng (1993) put forward the theory of "general input and precise input". Some scholars combine input theory with practical applications and discuss how to apply input theory in the classroom. Xu Haiming (1998) proposed that the form of classroom teaching should be valued, because only in the various environments in which learners who conform to Chinese situation can meet the input needs of learners to the greatest extent, can the input materials be fully prepared for learners. At the same time, he emphasized the role of output practice. The input material must be more difficult and hierarchical than the knowledge that learners have previously mastered, so as to promote better absorption of input. Some scholars have discussed the 
classification of language input. He Jianing (2002) proposed that the source of input can be classified. According to different classification methods, comparisons are made from content, intermediary, method, source and other aspects. Zhang Huanxiang (2004) put forward the theory of feedback and non-feedback. Other scholars have discussed how to create good opportunities and conditions for language input in foreign language classes from the perspective of information processing. The language input theory of second language acquisition has been widely used in the field of language teaching at home and abroad, especially foreign language teaching in middle schools and universities. Primary school English teaching started late, and the theoretical discussion of teaching is relatively weak. However, in terms of several methods widely used in primary school English teaching in China, the input teaching method can be well integrated. However, domestic research mainly focuses on two teaching methods: situational teaching and total physical response teaching.

\subsubsection{Situational Teaching}

At present, domestic research on input theory and situational teaching is mainly conducted by frontline teachers based on their own teaching experience. On the one hand, they affirmed the importance of situational teaching method in teaching, and on the other hand, they discussed how to effectively input students in the context of situational teaching method. Some scholars emphasize the fun of input. Zhang Zhiyuan pointed out, "Scenario setting should run through the entire learning process of learners, so that children's learning and language environment can have a contextual background, so that they can learn to be fun and easy to learn." Some scholars emphasize the interactivity of input. Zhang Hong (2010) and many other teachers in the front line of teaching have fully affirmed the effect and importance of situational teaching, and constantly promote the situational teaching method, especially in the design of the input link, to achieve interactive situational teaching and good results.

\subsubsection{Total Physical Response Teaching}

The total physical response teaching method can mobilize all parts of the body to receive language input. It emphasizes listening first and then imitating actions. It relieves the pressure of understanding and reduces the anxiety of learning. In a very real situation, it combines listening with doing, and then outputs speaking and writing. Under the background of total physical response teaching method, domestic scholars emphasize the importance of "comprehensible input". According to Gao Haifeng, second language acquisition is a complex process, in which a large number of effective input is an important factor affecting foreign language learning.
His paper "Krashen's input theory and higher vocational English Teaching" is based on Krashen's "comprehensible input" theory, combined with the characteristics of higher vocational students and higher vocational education, to explore practical and effective teaching methods and means, in order to improve the quality of Higher Vocational English classroom teaching. Therefore, multimedia should be used to strengthen the comprehensible input in English class, and the teaching mode should be reformed. At the same time, teachers should have the consciousness of providing "comprehensible input".

\subsection{The Output Theory to Primary English Teaching}

In the mid-1990s, Swain's output hypothesis theory began to attract the attention of domestic researchers and foreign language teachers. Domestic researchers of output hypothesis theory have conducted a lot of research and exploration to explore the relationship between output hypothesis theory and foreign language teaching, involving many aspects of foreign language teaching and research. Some scholars believe that language output helps learners' language learning. Wang Ying (2003) believes that outputting hypotheses, testing hypotheses, paying attention to metalanguage and automation functions play an important role in the cultivation of students' language awareness. Liu Fusheng (2004) proposed to strengthen the awareness of language output and pay attention to the form of language feedback. In the cognitive process, from passive output to subconscious learning and meaningful language, so as to improve the learner's ability of language expression. In terms of several methods widely used in primary school English teaching in China, the output hypothesis theory is also well integrated. For example, Cui Wenjuan (2007) is task-oriented and emphasizes the importance of the application of output theory in the article. Some scholars have carried out experiments to demonstrate the impact of output theory on English teaching.

Some scholars demonstrate the importance of output hypothesis theory in practical teaching from all aspects of teaching. Wang Sudan (2001) found through research that the phenomenon of influent classroom conversation is caused by lack of output. Zhao Ping (2000) emphasized the role of output hypothesis theory in guiding writing teaching by analyzing the writing process of students' composition. Man Li (2005) proposed a new teaching model of listening and speaking based on the theory of language input and output, which effectively eliminated the barriers of listening and speaking. In recent years, the output hypothesis theory has gradually gained attention in the field of language teaching at home and abroad, but also 
due to the late start of primary school English teaching, the discussion of teaching theory is relatively weak.

\section{THEORETICAL FRAMEWORK}

\subsection{The Input Hypothesis of Krashen}

In the field of second language acquisition, researchers have proposed a variety of theoretical models to explain the process of second language acquisition. In the 1980s, the American language theorist S.D. Krashen put forward five hypotheses that influence the mechanism of second language acquisition on the basis of absorbing the results of predecessors: The Acquisition-learning Hypothesis, The Monitor Hypothesis, The Natural Order Hypothesis, The Input Hypothesis and The Affective Filter Hypothesis.

\subsection{1 $i+1$ Hypothesis}

Krashen's input hypothesis believes that language acquisition is achieved through understanding, only when the learner is exposed to "understandable language input", that is, a second language input slightly higher than his existing language skill level, and he can Acquisition can only occur when the attention is focused on the understanding of meaning or information rather than the understanding of form. This is his famous " $i+1$ " hypothesis. i represents the current level of the learner, and 1 represents language materials slightly higher than the current level of the learner. According to Krashen, this kind of input does not need to be provided deliberately by people. As long as the learner can understand the input and he has a sufficient amount, the input is automatically provided, that is to say, learned The reader must first understand the meaning of the language, and the language structure will be naturally acquired. The "input hypothesis" also emphasizes that the ability to use language is not taught, it is naturally formed through exposure to a large amount of understandable input over time. It can be seen that understandable input is the key to language acquisition and the core of the "input hypothesis".

\subsubsection{The Affective Filter Hypothesis}

The Affective Filter Hypothesis was first proposed by Dulay and Burt in 1977 to reveal the influence of emotional factors on second language acquisition. The emotional filtering hypothesis holds that a large number of suitable input environments does not mean that students can learn the target language well. The process of second language acquisition is also affected by many emotional factors. Language input must pass through emotional filtering before it can become language "intake".
In the process of language input reaching the brain's language acquisition organs, filtering is the first obstacle that the input language information must overcome. In other words, emotional factors play a role in promoting or hindering. Krashen pointed out when summing up his past experience in second language teaching, in the process of acquiring a second language or foreign language, the learner does not absorb everything he hears. There are several psychological factors that affect the speed and quality of his language acquisition-Motivation, Character and Emotional State.

\subsection{The Output Hypothesis of Swain}

Swain put forward an intelligible output hypothesis through a survey of Canadian French immersion programs, and clearly stated that the output can promote the fluency and accuracy of the language expression of second language learners, but at the same time found a large number of language inputs and It does not necessarily lead to high-quality language output. Swain found that the main reason for this phenomenon is that students have too few opportunities for output, and they only stay at the level of understanding for input, and have not been internalized into their own knowledge, becoming a part of their internal cognition, so that they cannot fully use and develop their second language skills. Therefore, Swain proposed that only relying on "understandable input" cannot promote the overall development of the second language. If learners want to make their second language expressions fluent and accurate, they need "understandable output".

\subsubsection{Noticing Function}

Language output can prompt L2 learners to notice that there is a gap between what they want to express and what they can express. This gap makes them aware of the knowledge of the target language they don't know, and thus draws their attention to the language form. Richard Schmidt (1990) believes that attention is a necessary condition for input into absorption. Swain \& Lapki (1995) conducted a study of 8-year students in French immersion teaching with think around protocols to obtain information about learners' internal cognitive process and to test whether the output can draw their attention to their own language problems. The results show that learners are indeed aware of the problems in their own expression. It also activates the internal cognitive process related to second language acquisition.

\subsubsection{Hypothesis-testing Function}

Swain believes that the process of second language learning is a process of constantly putting forward hypotheses to the target language and constantly testing and correcting them, and output is an important means 
to verify the hypothesis. In the process of learning the target language, second language learners often test the form and structure of the target language by oral or written forms, and modify the errors or inappropriate expressions in the output through the direct or indirect feedback from peers, teachers or native speakers, so as to gradually improve their level of the target language and enable them to skillfully use the target language.

\subsubsection{Metalinguistic Reflective Function}

Metalanguage is the sum of language knowledge that learners have, that is, the rudimentary form of knowledge about language form, structure and other aspects of language system that learners obtain through reflection and analysis of language. When learners need to communicate, they will use the target language to communicate, that is, "output 1 " is produced. At this time, the output may have many problems, such as inaccurate grammatical form, inappropriate words, etc. Feedback from internal or external causes the speaker to consciously pay attention to the language form, he will analyze the language form used (simple inspection or careful thinking), if a solution to the problem is found, then the corrected output will be produced, namely "Output 2", thereby promoting the internalization of language knowledge; if you fail to find a solution to the problem, the communication task is not completed. In the future study, he will pay more attention to analyzing similar inputs to consolidate and improve his interlanguage system.

\subsubsection{Fluency Enhancement}

Language output can improve the fluency of expression. The more frequently the learner uses the language, the more fluency in the language can be obtained. Fluency is the development from controlled processing to automated processing. Therefore, increasing fluency does not simply mean speeding up speaking. Fluency is a sign of automated processing. We know that the human brain is a system with limited processing. Certain cognitive processes require a lot of time and a large amount of working memory capacity, while other cognitive processes are routine and automated, requiring less time and capacity. When there is a consistent and regular connection between a certain input and a certain output form, this process becomes automatic. Therefore, the consistent and regular successful mapping between output and grammar can lead to the automation of processing, thereby improving the fluency of expression, achieving fluency at a certain level can enable your attention resources to be used for information processing at a higher level.

\subsection{Theoretical Framework of This Article}

The main ideas of input theory are mainly reflected in the stretch-able second language acquisition theory in the 1980s, which contains five hypotheses: the learning-acquisition hypothesis, the monitoring hypothesis, the input hypothesis, the affective filter hypothesis and the natural order hypothesis. As for the learning-acquisition hypothesis, the learning process can be divided into two types: acquisition and learning. The former means that learners unconsciously grasp the meaning of language in actual communication under the influence of the surrounding environment or in conversations with others. Learning means that learners consciously learn a certain language under the organization of language rules by teachers. The acquired language deserves more attention in the process of expressing and understanding the meaning of the language and directly using it in actual communication, while the learned language pays more attention to the form and grammatical rules of the language and can only be used in real life after being absorbed.

The output theory mainly supplements the input theory and makes up the deficiency of the input theory. Output theory focuses on learners' ability to develop their own language style. Therefore, in teaching, the classroom should try to create a relaxed environment, encourage more students to output, and build output framework to assist students to output. Output can promote the development of students' reflective thinking and cultivate their critical thinking ability. By strengthening students' output consciousness and paying attention to the process of output, the balance between input and output can be achieved.

\section{RESEARCH ON PRIMARY SCHOOL ENGLISH INPUT AND OUTPUT TEACHING METHODS}

\subsection{Research on Primary School English Input Method}

The research on language input, output and interaction in China is mainly carried out from two aspects: theoretical introduction and discussion, empirical research and teaching practice. In the 1980s, Krashen's input theory was introduced into China and attracted extensive attention. Researchers mainly focused on the introduction and comments of this theory. Since the 1990s, with the introduction of output theory, researchers have also begun to explore the relationship between language output and teaching (Krashen. S., 1982). At the same time, domestic scholars also study the interactive hypothesis theory. Although The study of spoken Language started late in China, a series of achievements have been made. It mainly focuses on oral language teaching, oral language 
context research and oral language theory research. Krashen, an American linguist, put forward the checking theory, which emphasizes input in the language input hypothesis. In this process, he believes that language input materials can be understood, which is a necessary condition for improving the effectiveness of language learning (Krashen. S., 1982). Specifically, it means that in classroom teaching, the selection and use of language input materials should be based on learners' language knowledge reserve and expression level. However, it should be noted that the language input content should be slightly higher than the current language level. This is also the " $\mathrm{i}+1$ " language input principle proposed by Krashen in his input theory, where I refer to the current language learning water of learners, and this +1 refers to the level slightly higher than I. Therefore, the choice of teaching content should follow this principle. Otherwise, learners will have difficulty digesting the language knowledge. In addition, learners should have an intrinsic comprehensible language input acquisition mechanism. In other words, the judgment of $i+1$ requires the learner to make use of the known cognitive structure or in a specific context. At the same time, Krashen emphasizes the need to provide learners with real context, thus providing favorable conditions for effective language input.

In his input hypothesis, Krashen emphasizes comprehensibility, location and correlation, the detection procedure and sufficient input quantity, because these four factors have an important influence on comprehensible input. In terms of comprehensibility, it is important to ensure that language input materials are understandable to learners, which is more important for learners' language acquisition. Secondly, in terms of interest and relevance, newly printed corpus, which is closely related to learners' actual life or study, can more easily arouse their enthusiasm in language learning and actively participate in language practice activities. Thirdly, in terms of non-grammatical programs, Krashen believes that non-grammatical programs should not emphasize grammar too much in teaching. Finally, there are two aspects of language input. Krashen believes that learners should be provided with a large amount of language input materials.

\subsection{Research on primary School English Output Method}

On the basis of developmental immersion teaching, Swain, a Canadian scholar, proposed the well-known comprehensible output hypothesis theory. In the opinion, it is not enough for learners to successfully acquire language by relying on language input alone, and learners should also carry out comprehensible output. In other words, in addition to language input, learners also need to make effective use of the acquired language input materials, so as to complete a relatively complete language acquisition process (Swain. M, 1995).

In addition, Swain also summarizes the three main functions of understandable output, namely, the attention function, the hypothesis testing function, and the meta-language reflection function. These three functions are of great significance to learners: first, the function of attention. In language output activities, learners can be aware of the deficiencies of their own language expression and the gap between their own language expression and the target language. The second is the function of hypothesis testing. In the process of language learning, learners put forward hypotheses and test whether the hypotheses are feasible through oral and other output forms, which is helpful to improve the accuracy of learners' oral expression (Swain. M, 1995). The function of thirty-meta language reflection is to reflect on language only with existing language knowledge, so as to promote the control and internalization of language knowledge. Therefore, to give full play to the three functions of comprehensible output is beneficial to the cultivation of oral English expression ability of primary school students.

\subsection{The Relationship between Input and Output}

Equilibrium is a process in which individuals' cognitive development is transitive from one state of equilibrium to another state of higher equilibrium by means of self-regulation mechanism. Children's cognition is initially at a lower level of equilibrium. When faced with new and different stimuli, there is an imbalance. Through the interaction between subject and object, that is, through assimilation or adaptation, the cognition reaches a new level and restores the equilibrium state. The development of cognition is the process of balance - imbalance - balance.

Balance regulates an individual's cognitive process from three aspects: first, it regulates the relationship between the two skills of assimilation and adaptation to keep the two in balance; The second is the subsystem that regulates the different functions in the individual cognitive structure; Third, maintain balance in the differentiation and integration of individual knowledge.

Language input is an important prerequisite for language output, while language output is to express language input materials in other ways (Fillmore. W, 1985). The interactive hypothesis theory proposed by Long includes comprehensible input and effective output, and learners need to continuously enhance the comprehensible output, because language acquisition is the unity of language input and language output. Only by implementing the combination of language input and language output can the oral English expression ability be better improved. Among them, the theory of 
language input emphasizes the comprehensible input of new language knowledge and internalizes the explicit new language knowledge (Fillmore. W, 1985). In addition, the theory of language output emphasizes the effective use of the internalized language input materials in oral form according to the specific context.

\section{CONCLUSION}

Comprehensive language application ability includes listening, speaking, reading and writing, which are equally important. It has become an important goal in English teaching to cultivate the comprehensive language application ability of primary school students. Therefore, it has become an important focus of every English educator to cultivate pupils' oral English expression ability. As the main theory in the field of second foreign language acquisition, input and output theory is widely used in external teaching. In the cultivation of pupils' oral English expression ability, the input and output of oral English are two aspects. For pupils and English teachers, pupils' oral expression ability is mainly related to language input in winter, input conditions and input contents. The English language output part of primary school students includes output consciousness, output quality and output environment. Based on the input and output theory, four teaching strategies for the application of English resources are proposed according to the requirements of input and output theory for English teaching, which are respectively: creating a language environment, reducing emotional filtering, deeply understanding input, and multi-directional output. In the process of actual teaching, the final result can be effectively exported to the oral English of primary school students through the input of many different ways. After completing the education strategy of English resources based on input and output theory, students' learning interest can be improved to a certain extent and good results can be achieved in teaching performance. This shows that English teaching strategies based on input and output theory are feasible and instructive in practical teaching.

\section{REFERENCES}

[1] Basturkmen, Shawn Loewen, Rod Ellis. Metalanguage in Focus on Form in the Communicative Classroom. Language Awareness, 2002, 11(1):1-13.

[2] Brown R. Group Work, Task Difference, and Second Language Acquisition. Applied Linguistics, 1991, 12(1):1-12.

[3] Cui, W.J. Language output theory and task-based language teaching. Journal of Sichuan College of Education, 2007.

[4] Ding, G.C. Talking about language input in communicative teaching. Foreign Language Circles, 1993(4): 24-26.

[5] Doughty, C\&J. Williams. Focus on Form in Classroom Second Language Acquisition. New York: Cambridge University Press, 1998.

[6] Ellis, R. Instructed Second Language Acquisition: Learning in the Classroom. Oxford: Basil Blackwell,1990.

[7] Fillmore, W. "When does teacher talk work as input?". In Input in Second Language Acquisition, Edited by: Gass, S.M. and Madden, C.G.Rowky, MA: Newbury House Publishers, 1985.

[8] Hamer, J. How to Teach English. Beijing: Foreign Language Teaching and Research Press, 2012.

[9] Hawkey, R. Teacher and Learner Perceptions of Language Learning Activity. English Language Teaching Journal, 2006, 60(3):242-252.

[10] He Jianing. The Necessity, Fields and Methods of Dictionary Use Research. Dictionary Research, 2002(04):136-141.

[11] Liu, F.S. Research on "Language Output". Journal of Southwest University for Nationalities: Humanities and Social Sciences Edition, 2004.

[12] Krashen, S. Principles and Practice in Second Language Acquisition. Oxford: Pergamon Press, 1982.

[13] Krashen, S. Principles and Practice in Second Language Acquisition. Internet Edition, 2009.

[14] Man, L. Input and Output Theory and Listening and Speaking Training. Journal of Taizhou University, 2005, 27(002):54-57.

[15] Spada, N. Beyond Form-focused Instruction: Reflection on past, present, and future research. Language Teaching, 2011, 44:225-236.

[16] Swain, M. Communication competence: Some Roles of Comprehensible Input and Comprehensible Output in its Development. Input in Second Language Acquisition. Boston: Heinle\&Heinle, 1985.

[17] Swain, M. For H.G. Widdowson: Principles and Practice in the Study of Language. Oxford: Oxford University Press, 1995.

[18] Swain, M. Three functions of output in second Language learning. Principles and Practice in Applied Linguistics. Oxford: Oxford University Press, 1995.

[19] Swain, M.\&S. Lapkin. Problems in output and the cognitive processes they generate: a step towards 
second language learning. Applied Linguistics, 1995 (16) :371-391.

[20] Wang, S.D. Input and Output: An Analysis of Unfluent English Classroom Conversation. Journal of Hengyang Normal University, 2001(01):122-124.

[21] Wang, Y. Overview of the Pragmatic Studies of Discourse Markers. Southwest China Normal University, 2003.

[22] Xu, H.M. Language Input Theory and Foreign Language Learning. Journal of PLA University of Foreign Languages, 1998.

[23] Zhang, H. Research on the Application of Situational Teaching in Primary School English Classes. Shanghai Normal University, 2010.

[24] Zhang, H.X. On the Classification of Language Input. Journal of Shandong Normal University School of Foreign Languages (Basic English Education), 2004, 000(001): 15-16.

[25] Zhao, P. The significance of Swain's output hypothesis for college English writing. Shandong Foreign Language Teaching, 2000, 000(003): 80-83. 